\title{
Relational geographies of knowledge and innovation
}

\author{
James R Faulconbridge
}

\section{Please cite as:}

Faulconbridge JR (2017) Relational geographies of knowledge and innovation. In Bathelt, $\mathrm{H}$. Cohendet, P. Henn, S. and Simon, L (Eds) The Elgar Companion to Innovation and Knowledge Creation. Edward Elgar, 671-684.

\section{Introduction}

This chapter explores how economic geographers have developed a relational perspective on knowledge and innovation, and the implications of this perspective for management in organizations and for public policy.

For economic geographers, interest in knowledge and innovation is mediated through two spatial lenses. First, an interest in sites of knowledge and innovation, this being seeded in particular through studies of regional agglomeration and localization economies (Storper and Christopherson 1987; Henry and Pinch 2000). Most recently this lens has been deployed to analyse clusters as geographical notes of knowledge and innovation (Pinch et al. 2004). Second, questions about firms have drawn attention to the spatiality of the communities in which knowledge and innovation 'happen' (Amin and Cohendet 2004, Faulconbridge 2010). Both of these lenses have contributed to the development of relational perspectives in which focus falls on "economic and social relations, processes of organizing, problem solving, and innovation, as well as on the creation of informal and formal institutions" (Bathelt and Glückler 2005, 1546).

The relational perspective offers a number of unique insights into knowledge and innovation. In particular, it allows both the social and the spatial dimensions of knowledge 
and innovation to be simultaneously addressed through a perspective that shifts focus "from the macro-level...to the micro level (i.e. agents and their interactions) (Boggs and Rantisi 2003, 111). This involves analysing through fine-grained and often qualitative studies the way knowledge and innovation are innately shaped by the contexts in which they are produced; context in this sense being both a social and spatial dimension. As Bathelt and Glückler (2005) note though, this micro-scale focus is not restricted to phenomenological accounts of action. It also seeks to reveal how analysis of the micro-scale can contribute to understanding of the macro-scale in the sense of institutional effects.

The remainder of this chapter seeks to unpack the way that the relational approach can, therefore, provide a distinctive way of understanding knowledge and innovation as processes. It also reflects on the implications of a relational perspective for how knowledge and innovation might be managed in organizations and through policy. As such, the main contention of the chapter is that the relational approach offers a unique perspective that can bring both people and places to the forefront of studies, this being beneficial because of the significance of socio-spatial collaboration to effective knowledge and innovation production.

The chapter proceeds as follows. The next section outlines the origins of the relational approach and its key principles. This is followed by analysis of the implications of the relational perspective for understandings of knowledge and innovation. Two sections then in turn consider how relational insights can be used to better manage knowledge and innovation in organizations and through policy, before the concluding sections consider the future directions for relational research on knowledge and innovation.

\section{Relational perspectives}


The relational turn in economic geography has been inspired by and contributed to similar turns across the social sciences, including in other parts of geography (Jones 2009), in sociology (Emirbayer 1997) and in management (Uzzi and Lancaster 2003). As Boggs and Rantisi (2003) note, motivations for a relational turn are multiple. First, corporate organization has become increasingly relational. As part of processes of vertical disintegration and the externalization of activities to sub-contractors, something being especially significant in generating growth in the service economy (see Goe 1991), relationships between firms have become increasingly significant in determining innovation capacity. Miles (2001) argues that innovation now increasingly involves collaboration between firms as, in particular, knowledge-intensive business services (but also subcontractors providing components in manufacturing (see Dicken 2011)) collaborate in a coproduction process. As a result, understanding the nature of these relationships is crucial.

Second, and in line with a shift to the micro-scale, focus has fallen upon the way agency at the level of individual actors and groups matters in economic activity. As part of efforts to understand firms as social communities (Cohendet and Llerna 2003; Morgan 2001) it has been emphasised that understanding the dynamics of social action, and the way it is constrained by but also has the potential to exert influence over corporate structures and societal institutions (Archer 2000), is an essential part of understanding economic competitiveness. Relational perspectives take this agency seriously and examine what constitutes and constrains it.

Third, the emergence of a global space economy has refocused attention on the importance of analysing the spatiality of corporate practice (Jones, 2008). Of course, spatiality always mattered. Marshall's (1890) observation that the secrets of regional economies were 'in the air' set the scene for research that considered the importance of local relationships for knowledge and innovation. However, with globalization came a new 
imperative to understand internationally stretched relationships. As Amin and Cohendet (1999) noted, in the global era it was no longer tenable to understand firms as 'islands' of innovation. Rather, decentralised business networks, between subsidiaries of global firms but also involving traded and untraded relations with other firms and individuals, became of interest. Hence relational approaches took on a new spatial significance, being a crucial way of understanding the extent to which processes of knowledge and innovation found at the local scale (intra-firm or locality) could be reproduced across space (Gertler 2003).

\section{Principles of the relational approach}

A number of core principles of analysis have developed which are significant for how knowledge and innovation might be studied and conceived of relationally. First, in developing the micro-scale perspective, the socio-cultural constituents of economic practice are prioritised (Jones and Murphy 2011). This has taken a number of forms. For Ettlinger (2003) the cultural turn within economic geography (Barnes 2001) and the prioritisation of how culture shapes the 'relational microspaces' of interaction within firms provides a way to make sense of how issues such as trust and reciprocity influence economic practice. Gertler (2003) offers a parallel but subtly different perspective, arguing that culture needs to be understood as being related to institutions, this helping reveal how all interactions are geographically situated.

In addition, a growing body of work has drawn attention to how power relations are fundamental to economic practice. This has involved conceptualising power itself as relational (Allen 2003); the social interactions that define innovation thus being means through which power is both exercised and constructed (Faulconbridge 2012). The major advantage of this focus on the socio-cultural constituents of practice is that it allows the 
contingency of relational action to be accounted for in analyses of the determinants of successful innovation practice.

A second core principal of relational approaches relates to understandings of spatiality. In an effort to move beyond regional science perspectives that understand spatiality as a pre-existing container, relational approaches conceive of space as continually produced by economic action (Bathelt and Glückler 2003, Yeung 2005). This socially constructed view conceives of spatiality as defined by social agency; actions and interactions constitute the space in which knowledge and innovation occur. For instance, Amin and Cohendet (2004) in their communitarian approach highlight the architectures and infrastructures which generate relational spaces of knowledge, these being both social (collaborations and relationships) and material (informational technology networks and circulating documents). Crucial for Amin and Cohendet (2004) is the topological nature of relational spaces, being as they are defined by the complex criss-crossing of different social and material relations. This means knowledge and innovation is associated not with predefined spaces, such as the city, region, country or organization, but by spaces that are constantly being produced and reproduced through social agency. Using the case of global architecture firms, Faulconbridge (2010) shows that this can result in communities and constellations of practice emerging that generate spaces of knowledge and innovation unhindered by geographical distance. Underlying such spaces are complex assemblages of social collaboration (e.g. project meetings, corporate away-days) and non-human connectivity (e.g. video conferences, circulating building models).

Ultimately, the socially constructed understanding of spatiality adopted in the relational perspective reconfigures conceptions of the sites of knowledge and innovation. It frees analyses from the shackles of a container view of spatiality which tends to lead to assumptions about the localness of knowledge and innovation practice (Bathelt et al. 2004, 
Faulconbridge 2006). In particular, the relational perspective emphasises the need for spaces of knowledge and innovation to be created, and that this creative process has the potential to connect together into communities individuals located both in proximity and at a distance (Faulconbridge 2007a, Vallance 2011).

The third key principal of the relational approach relates to research methodology. As a result of the focus on culture, power and social action, research has emphasised the importance of fine grained qualitative studies. Whilst accepting that as far back as Granovetter's (1985) work relationality has been studied through quantitative means, economic geographers have emphasised the value gained from studying the intricacies of situated economic action. Yeung (2003) thus called for a tracing of actor networks through the triangulation of various data sources, including documents, interviews and participant observation. Each method should be deployed at each of the different sites connected together by relational action and should seek to reveal the contingencies shaping outcomes. As Faulconbridge (2012) notes, such an approach requires the researcher to operationalise and triangulate qualitative methods effectively, something economic geographers have not always been good at. It also requires attention to be paid to the outcomes of economic action and not just the contingencies of it. Bathelt and Glückler (2005) remind us that a focus on the microscale should not be at the expense of an understanding of the macro-scale implications. When such factors are taken account of, fine grained qualitative research has the potential to reveal much about the practice and spatiality of knowledge and innovation.

\section{Knowledge and innovation viewed relationally}

What, then, are the implications of the principles of the relational approach outlined above for perspectives on knowledge and innovation? To address this question requires consideration 
of three important issues: What is knowledge, how are knowledge and innovation produced, and what determines the spatiality of knowledge and innovation?

In terms of the nature of knowledge, relational perspectives complement the practice turn in approaches to understanding knowledge and innovation. Heavily influenced by the seminal work of Lave and Wenger (1991) and latterly Wenger (1998), the practice approach has been extended beyond its communities of practice origins into a broader practice-theoretical framing which sees knowledge and learning as constituted through embodied social action (Brown and Duguid 2000, Gherardi and Nicolini 2000, 2006). In such a perspective, knowledge is viewed not as a static commodity or resource, but as a dynamic social accomplishment that is always in the making. As Amin and Cohendet (2004) describe, both relational and practice perspectives dismiss the idea that knowledge exists as an economic artefact which can, for instance, be 'held' by an individual, company or in a database. Instead, they understand knowledge to be collectively produced and shared by social communities in an ongoing manner. This means transcending common distinctions between tacit and explicit knowledge and recognising that because of its social nature knowledge always has both tacit and explicit dimensions.

For Brown and Duguid (2000), the practice informed understanding is best captured by a shift from the use of the term knowledge to the use of knowing. By adopting the verb form the intention is to highlight the significance of social action for creating, maintaining and reproducing knowledgeability. This view of knowledge, which departs in significant ways from perspectives adopted in many knowledge management literatures in which knowledge is viewed as an asset to be captured, stored and disseminated, has important implications for perspectives on how knowledge and innovation are produced. Specifically, social practice is seen as the means by which knowledgeability emerges and innovations are generated. 
As already noted, work of communities of practice provides the basis for much of the practice based thinking. In Wenger's (1998) development of the communities of practice idea, he highlights how interactions between community members allow learning and the production of knowledge. Three contingencies are said to affect these interactions and make knowledge production possible. First, those interacting must have a mutual engagement, this referring to involvement in a similar activity. Second, joint enterprise is important, this being a common way of understanding and completing the activity in question. Third, shared repertoires are needed, these being constituted by common languages, tools or procedures. Whether an individual becomes a member of a community of practice, and in turn helps generate new knowledge, depends on the extent which each of the three contingencies is fulfilled. As such, the three contingencies, because they shape crucial social interactions, determine the success of the production of knowledge and innovation.

Others have since added a number of further dimensions to Wenger's (1998) analysis of communities of practice. Fox (2000) points out that power-relations need to be accounted for, with interactions in communities being shaped in important ways by both resource inequalities and discursive efforts at control that can lead to exclusion from communities. Amin and Roberts (2008) highlight the subtly different nature of interactions depending on the characteristics of the knowledge being produced in a community. By contrasting craft, professional, creative, and virtual communities and their different forms of knowledge and means of social interaction, Amin and Roberts show that learning in practice can take radically different forms, from intensive master-apprentice embodied interactions in craft industries to fleeting virtual interactions in online communities. Such refinements of understanding of the social interactions that allow knowledge and innovations to be produced confirm the significance of the emphasis placed in the relational approach on studying the contingencies of social engagement. 
Relational approaches have also developed the practice inspired approach outlined above in terms of understandings of the spatial dimensions of communities. As part of an agenda to move beyond an initial fetish with the local scale in which knowledge and innovation was assumed to require the co-location of interacting parties, studies have examined the way that the social interactions which produce community spaces of knowledge and innovation can be stretched (for summaries of this agenda see Bathelt et al. 2004, Faulconbridge 2006, Vallance 2011). Focus has fallen on two fundamental questions about such stretching.

First, what is the spatiality of the means of interaction that allow knowledge and innovation to be produced? In work which emphasised the localness of knowledge and innovation, face-to-face contact and embodied encounter was emphasised as crucial for allowing the social action that creates, maintains and reproduces knowledge (Storper and Venables 2004). The relational approach has questioned such assumptions, and demonstrated that interaction need not occur solely between co-located individuals. Studies have shown that the architecture of knowledge and innovation "includes, yes, face-to-face meetings, sociality, and casual contact...but it also draws on distant objects such as drawings faxed between offices around the world, global travel to form temporary project teams, and daily internet/telephone/video conversations" (Amin and Cohendet 2004, 110). In highlighting this, and in line with the relational perspective's understanding of space as socially constructed, research encourages the tracing of practice to identify the geographies of knowledge and innovation, which can be both local and global (Bathelt et al. 2004; Faulconbridge 2007a).

The second fundamental question about spatiality relates to the contingencies that underlie more or less local knowledge production and innovation. Reflecting the ideas outlined above about the range of factors that can affect interactions, research has sought to clarify whether physical proximity renders knowledge and innovation production more 
effective. For instance, reflecting ideas in work on communities of practice, the idea of relational proximity has been developed (Blanc and Sierra 1999) to take account of the way mutual engagement, joint enterprise and shared repertoire can exist between both spatially proximate and distanciated individuals. In particular, various means of creating relational proximity have been noted.

Gertler (2008) argues that proximity can emerge as a result of shared social affinities such as common educational background, work experience or occupation. Faulconbridge (2006, 2010) suggests that in multinational corporations relational proximity can be manufactured through strategies such as common corporate languages, globally stretched project teams, and the circulation within the firm of handbooks and other objects which create a common reference point. In terms of questions about culture and power, literatures suggest that a key priority is managing the effects of these on social interactions. For example, Gertler (2004) shows that culture determines whether differently situated individuals and communities can learn from one-another and whether opportunities for innovation are spotted. Faulconbridge (2008) shows that cultural difference requires negotiated compromises between actors in different subsidiaries of multinational firms, these compromises facilitating collective learning and innovation in some cases but in others preventing the sharing of ideas and expertise. Boussebaa (2009) points out that in global teams innovation can be impeded by power relations and politics that render collaboration more difficult than it might be, these power relations often being geographical in form as they relate to neo-colonial core-periphery relationships (such as between Western and Eastern European team members).

In sum, as explored further below, the relational approach suggests that it is crucial to study and manage the social interactions and their contingencies that are fundamental to knowledge and innovation. Of course, not all of these interactions will be at a distance - the 
relational approach has tended to focus on distanciated interactions because of a desire to better understand the spatiality of knowledge and learning. As Asheim et al. (2007) point out, depending on the nature of the knowledge being produced and informing innovation, interactions and the resultant spatiality may be more or less local. Asheim and colleagues differentiate between analytic, synthetic and symbolic knowledge bases, each they suggest being associated with different kinds of industry (for instance the life sciences, furniture manufacturing, and film production industries respectively). Analytical knowledge bases tend to be comprised of more formalised knowledge, for example captured in patents, whilst synthetic knowledge bases involve applying formal knowledge in creative way. Symbolic bases are reliant more on the craft skill of individuals. Asheim et al (2007) argue that an industry with an analytical knowledge base is more likely to be able to engage in spatially stretched processes of knowledge and innovation production as embodied encounter is less important for learning than in industries reliant on synthetic and symbolic knowledges. It is debatable whether any industry first perfectly into the typology proposed by Asheim et al. (2007), but the important point to emerge from their analysis is that the relational geographies of knowledge and innovation are potentially both local and global depending on both the contingencies of social interaction described above and the nature of the knowledge being produced and informing innovations.

\section{Managing knowledge and innovation in organizations: a relational viewpoint}

The analysis above reveals a number of distinctive features of the relational perspective that have implications for managing knowledge and innovation in organizations. As already noted, most fundamentally the approach suggests knowledge itself cannot/should not be managed. Rather it is the social interactions between individuals that need attention. In 
particular, it is the occurrence and effectiveness of these interactions that should be of concern. For researchers, this means adopting a methodology capable of unpicking the forms and contingencies of social interaction. Two examples from the literature that adopt a relational perspective usefully illustrate these points.

Wood and Reynolds (2012) consider the case of store location decisions in retail firms and the way knowledge that informs decision-making is developed. They observe that "Clearly the management of interaction between different communities within the firm presents significant challenges" (page 554), power relations between groups within the same organization being the most important consideration when seeking to generate the collaboration needed to produce knowledge that will inform effective decision making. Wood and Reynolds (2012) conclude that organizations must, therefore, put in place strategies that ensure individuals from different departments are able to interact effectively. A focus on developing supportive corporate cultures can be one means of achieving such interactions, Cohen and Levinthal (1990) long ago identifying this as being key to the 'absorptive capacity' of an organization. The boundaries of the community of interacting agents must also be fluid, allowing different people to contribute as and when useful and ensuring participation is not exclusive. Wood and Reynolds $(2012,20)$ thus conclude by agreeing with Amin and Cohendet's $(2004,12)$ suggestion that a "common anthropology of socialization, social interaction, interest alignment, and community maintenance" are fundamental to effective knowledge production.

Faulconbridge (2010) offers a different set of insights by examining global communities of practice in architecture firms. By examining the way that firms seek to generate collaborations between professionals employed in offices around the world, the case reveals the role of combinations of the social affinities Gertler (2008) outlines, deliberate corporate strategies to generate relational proximity, and crucially non-human objects that act 
as boundary spanners between distributed agents. In particular, the case reveals that in multinational organizations there is likely to be some of the social infrastructure needed for effective innovation, such as individuals with shared educational backgrounds and professional memberships, but that efforts also need to be made to bolster relational proximity by generating the mutual engagement, joint enterprise and shared repertoire crucial to the success of communities of practice. These efforts can take various forms. For instance, allowing business travel and organizing firm-wide conferences provides an opportunity for individuals to interact in person as well as virtually, this helping overcome some of the cultural and power related contingencies discussed previously. In addition, Faulconbridge (2010) highlights the role of non-humans, in the case of architecture firms these being combinations of documents (corporate newsletter, building blueprints etc) and models of buildings which circulate between offices and help build relational proximity.

The two cases outlined above are significant in that they draw attention to three key implications of the relational view. First, they show the value of a communitarian perspective which recognises that firms, and equally the cities and regions documented in the cluster literatures, are actual social communities rather than hollow structural or spatial containers. When viewed as communities attention shifts to the identities but most crucially the relationships between individuals who can produce knowledge and innovation through interactions. As a result, there is an emerging literature in human resource management that argues that knowledge management is a task not for dedicated departments (often staffed by computer experts) but for human resource managers who manage the culture of the firm and the development of its employees (Sparrow, 2012). Second, the two cases reveal that there is always the potential for frictions in the interactions that produce knowledge and innovation, but these can be a productive part of the process. One of the strengths of the relational approach is its ability to understand the contingencies of these interactions, with the role of 
culture, power and forms of relational proximity all becoming clear thanks to the micro-scale approach adopted. This reemphasises the point that in managing knowledge and innovation the social conditions that facilitate the social processes of their production should be atop of agendas.

Third, the cases reveal the potential of the relational approach to explore knowledge and innovation production as processes that are similar regardless of whether community members are co-located or not. By de-emphasising face-to-face and embodied interactions, and emphasising the social conditions discussed in the previous points, the relational approach helps reveal the potential for criss-crossing local-global geographies of innovation, and challenges presumptions that local, face-to-face mediated encounters are always most productive (Faulconbridge 2007a). The relational view offers, therefore, a means of decentring the firm, region and knowledge itself as part of efforts to recognise the 'social life' of knowledge and innovation (c.f. Brown and Duguid 2000).

\section{Relational policy}

The insights of the relational approach outlined above present two significant challenges to ways of thinking about public policy designed to encourage innovation. First, they reconfigure the priorities of regional innovation policies by emphasising the importance of social interaction. Second, they give parity to extra-regional networking as the connection of individuals and groups in one region to those in others emerge as crucially important. These two challenges are explored further in the next two sub-sections of the chapter. 
The relational perspective outlined in this chapter suggests that building material infrastructures, such as science parks, and providing tax relief for innovating firms, might be usefully complemented by strategies designed to seed and manage the kinds of social interactions that produce knowledge and innovations. This means enabling interactions that transcend the boundaries of firms and produce a regional ecology of knowledge. For instance, studies have shown that supporting the formation of effective regional communities of practice that allow those in related industries to collectively address economic and societal challenges is a productive use of policy resource (Benner 2003; Faulconbridge 2007b). In such communities there needs to be suitable cultures and power relations to facilitate open collaboration, something that can be strategically managed. The benefit likely to be gained from policies designed to seed interaction and collaboration is knowledge production and innovation that is more path-breaking than that constrained by the boundaries of a single organization.

As such, there is an imperative for policy to 'get inside' the corporations operating in any locality and dissolve boundaries between the organisations and the local community. Clearly questions of competitive advantage and intellectual property pose some hurdles to such work. But, using policy to ensure the engendering of a sense of membership of a community in those managing and working in firms, celebrate the successes of inter-firm collaboration, and develop an agenda for the locality that all firms can somehow shape, own, and ensure the success of, can provide a means of ensuring the inner walls of corporations are penetrated and intra-regional relationality constructed. This in turn would allow the spurring of the inter-firm social interactions that the relational view tells us is so important.

For corporations themselves, this means recognising that success is reliant as much on interactions beyond the boundaries of the firm as within. Too often in relation to questions about knowledge and innovation the focus falls on intra-organisational issues of knowledge 
management. Whilst not unimportant, the relational approach draws attention to the need to manage interactions not only between spatially separated entities in the same organisations, such as subsidiaries in different parts of the world, but also between the firm and its suppliers, competitors, and customers. As such, dissolving the boundaries of the firm to ensure that employees interact and learn with other firms in the locality, in the same industry, and in different industries is crucial. This would support the kinds of regional policy outlined above, and involve firms enabling, incentivising, and rewarding collaborations, whether through conference activities, working group membership, or virtual or face-to-face forums. Only by developing the kinds of relational interactions described here as at the centre of processes of learning and innovation can corporations hope to prosper in the knowledge based economy.

\section{Extra-territorial relational policy}

The discussion above of managing interactions within a locality is, not, however, to suggest that policy should solely focus on the local scale. Indeed, an important insight of the relational approach is that local fetishes potentially lead to missed opportunities in terms of stretched relational spaces of innovation. There is, then, a need to recognise the limitations of the cluster inspired approach to local/regional development (Martin and Sunley 2003). For firms and regions to avoid local lock-in it is necessary to explore policy that effectively builds stretched relational spaces of knowledge and innovation which connect firms and localities into global networks of related organizations. In many ways there is nothing new in recognising this; Amin and Thrift (1992) long ago documented that Marshallian nodes of innovation are reliant on global networks for their competitiveness. What is newer, however, is to suggest policy should invest in such global networks as well as local infrastructures. 
What might extra-territorial relational policy look like? Tactics might include networking activities for individuals and firms, such as trade conventions that create moments of temporary proximity and allow immediate but also more sustained longer term interactions between individuals within firms from around the world (Bathelt and Schuldt, 2008). It may also mean loca development agencies stimulating investments by multinational firms. For the multinationals, presence in a locality provides access to 'listening posts' which can inform innovations. For other firms in the locality, the multinational provides a connection into global knowledge pipelines that help generate novel innovations (Maskell 2014). The aim of policy initiatives should, then, be to spur effective forms of local-global interaction that help form a community of practice that can be maintained virtually over time. Policy must, of course, therefore also avoid multinationals simply exploiting the locality, as tax incentives or forms of labour arbitrage tend to encourage (Faulconbridge 2015), the basis for this being the encouragement of investments by multinationals seeking to contribute to the development of a critical mass of industry specialisation in a region, not simply extract cost savings or resource access.

This implies, then, that territorial policy itself needs to be conceived of through a relational lens. On the one hand this means, as outlined above, thinking about how policy can envisage a locality's place in wider national and international networks, and then support the development of a relational architecture which allows interactions that enable learning and innovation. On the other hand, it implies thinking relationally about the process of producing policy itself. As the growing body of work on policy mobilities attests (for a synopsis see McCann 2011), it is increasingly difficult to envisage policy being produced in a local vacuum given the influence of various circuits of policy knowledge that lead to ideas and practice moving around the world. It thus seems important to stay alert to the influences on the policy production itself of relational learning, this requiring policy makers to interact with 
their counterparts elsewhere as part of a process of both shaping the characteristics of policy and ensuring the relational networks discussed above are realised.

In addition, there also needs to be recognition of the potential to generate significant tangible effects through relational policy making on the local economy and/or global institutional infrastructure (Bathelt and Glückler 2005). Locally this might mean new rules of the game as far as collaboration, investment and skill development are concerned as firms respond to insights gained from interactions by reconfiguring priorities and practices. Ultimately this might lead to global competitive advantage for a region in a particular industry. Globally the result might be the emergence from communities of new transnational product standards, modes of market governance, or industry protocols. The outcomes will differ from case to case, but the important point is that relational interactions always have effects that should not be underestimated. Indeed, one of the critiques developed by work on policy mobilities is that relational policy making can lead to the importing of ideas unsuited to a locale or which replicate undesirable social and economic effects. This reminds us, then, that whilst the discussion in this chapter has been about the benefits that relationality can bring for learning and innovation, there is a darker side in terms of the potential for the spread of ideas and limited critical reflection on their merits and local impacts.

\section{Conclusions}

This chapter has considered the insights that a relational perspective on knowledge and innovation provide. It has drawn on the key tenets of the relational approach, namely that research should focus on social interaction, the way spatiality is constructed through this social interaction, and therefore adopt a micro-scale methodology, to argue that rather than studying knowledge and innovation themselves, the social interactions that produce them 
should be the primary concern of researchers. There is, of course, still much to do to leverage the relational perspective outlined here. As noted, the methods needed to effectively study the interactions underlying knowledge and innovation production are in need of further development, something that requires more longitudinal and in-depth case study based research (Faulconbridge 2012). There is also a need to better compare and contrast proximate and distanciated interactions. The question is no-longer whether one is more valuable than the other, but whether it is possible to more effectively differentiate the two both in terms of means and ends. The different roles and means of interaction of actors, from individuals to professional associations, firms to online communities, in local and global knowledge production and innovation also warrant further unpacking so as to better inform policy interventions that target and leverage these agents. In effect, future research needs to further unpack the three fundamental principles of the relational approach to add more fine grained understanding of how knowledge and innovation and produced through social interaction.

From a policy perspective, the relational approach provides two substantive challenges. First, the unit of analysis in terms of policy effects is transformed by the emphasis in the relational approach on social interactions. This implies that focus should fall not just upon hard infrastructure, investment in knowledge assets such as R\&D centres, and attracting talented workers. In addition, it is necessary to consider the opportunities, incentives and rewards for collaboration within the region and the kinds of social exchanges that enable learning. The means seeding collaboration and exchange, and perhaps most importantly developing the institutional thickness that allows rivalries to be put aside when individuals from competing firms come together. Such softer infrastructures necessitate a different kind of investment that, whilst hard to render tangible and measure, is according to the relational approach fundamental to innovation. Second, the relational approach requires the re-scaling of policy foci, away from cities and regions and towards relational topologies of 
collaboration. This does not mean 'local' development agencies and agendas need to disappear. Rather, it means the success of these local agencies and agendas must be recognised as intimately tied to the national and global relational ties of the locality. Developing such a perspective on and approach to policy is innately tricky given the territorialised nature of states, but is crucial and at the heart of the success of innovation sites in the global economy.

The relational approach provides, then, both a theoretical-conceptual-methodological mode of analysis in relation to issues of knowledge and learning, but also an orientation to policy that unsettles some of the more static and localised visions that exist in some literatures. As such, it provides a powerful way of reimagining questions about knowledge and innovation so central to contemporary economies.

\section{References}

Amin A, Cohendet P (1999) Learning and adaptation in decentralised business networks.

Environment and Planning D: Society and Space 17 87-104

Amin A, Cohendet P (2004) Architectures of knowledge: Firms capabilities and communities. Oxford: Oxford University Press

Amin A, Roberts J (2008) Knowing in action: Beyond communities of practice. Research policy 37 353-369

Amin A, Thrift N (1992) Neo-Marshallian nodes in global networks. International Journal of Urban and Regional Research 16 571-587

Archer M S (2000) Being human: the problem of agency. Cambridge: Cambridge University Press 
Asheim B, Coenen L, Vang J (2007) Face-to-face, buzz, and knowledge bases: sociospatial implications for learning, innovation, and innovation policy. Environment and Planning C: Government and Policy 25 655-670

Barnes T J (2001) Retheorizing economic geography: from the quantitative revolution to the “cultural turn". Annals of the Association of American Geographers 91 546-565

Bathelt H, Glücker J (2005) Resources in economic geography: from substantive concepts towards a relational perspective. Environment and Planning A 37 1545-1563

Bathelt H, Glückler J (2003) Toward a relational economic geography" Journal of Economic Geography 3 117-144

Bathelt H, Malmberg A, Maskell P (2004) Clusters and knowledge: local buzz, global pipelines and the process of knowledge creation. Progress in Human Geography 28 31-56

Bathelt H, Schuldt N (2008) Between Luminaires and Meat Grinders: International Trade Fairs as Temporary Clusters Regional Studies 42 853-868

Benner C (2003) Learning communities in a learning region: the soft infrastructure of crossfirm learning networks in Silicon Valley. Environment and Planning A 35 1809-1830

Blanc H, Sierra C (1999) The internationalisation of R\& D by multinationals: a trade-off between external and internal proximity. Cambridge Journal of Economics 23 187-206

Boggs J S, Rantisi N (2003) The 'relational turn' in economic geography. Journal of Economic Geography 3 109-116

Boussebaa M (2009) Struggling to organize across national borders: The case of global resource management in professional service firms. Human Relations 62829

Brown J S, Duguid P (2000) The social life of information. Boston, MA: Harvard Business School Press

Cohen W M, Levinthal D A (1990) Absorptive capacity: a new perspective on learning and innovation. Administrative Science Quarterly 35 128-152 
Cohendet P, Llerena P (2003) Routines and incentives: the role of communities in the firm. Industrial and corporate change 12 271-297

Dicken P (2011) Global Shift (6th edition. London: Sage

Emirbayer M (1997) Manifesto for a relational sociology. American Journal of Sociology 103 281-317

Ettlinger N (2003) Cultural economic geography and a relational and microspace approach to trusts, rationalities, networks and change in collaborative workplaces. Journal of Economic Geography 3 145-171

Faulconbridge J R (2006) Stretching tacit knowledge beyond a local fix? Global spaces of learning in advertising professional service firms. Journal of Economic Geography 6 517540

Faulconbridge J R (2007a) Exploring the role of professional associations in collective learning in London and New York's advertising and law professional service firm clusters. Environment and Planning A 39 965-984

Faulconbridge J R (2007b) London and New York's advertising and law clusters and their networks of learning: relational methodologies and scalar reflections. Urban Studies 44 $1635-1656$

Faulconbridge J R (2008) Negotiating cultures of work in transnational law firms. Journal of Economic Geography 8 497-517

Faulconbridge J R (2010) Global architects: learning and innovation through communities and constellations of practice. Environment and Planning A 42 2842-2858

Faulconbridge J R (2012) Economic geographies of power: Methodological challenges and interdisciplinary analytical possibilities. Progress in Human Geography 36 734-756 
Faulconbridge JR (2015) Communities within and without of the corporation: control, power, and interests. In Baars G, Spicer A (Eds) The critical Corporation. Cambridge: Cambridge University Press

Fox S (2000) Communities of practice, Foucault and actor-network theory. Journal of management studies 37853 - 866

Gertler M (2003) Tacit knowledge and the economic geography of context, or the undefinable tacitness of being (there). Journal of Economic Geography 3 75-99

Gertler M (2004) Manufacturing culture. Oxford: Oxford University press

Gertler M (2008) Buzz without being there? Communities of practice in context. In Community, economic creativity and organization Eds A Amin, J Roberts (Oxford: Oxford University Press, 203-226

Gherardi S, Nicolini D (2000) To tranfer is to transform: the circulation of safety knowledge. Organization 7 329-348

Gherardi S, Nicolini D (2006) Organizational knowledge: The texture of workplace learning. Oxford: Blackwell

Goe W (1991) The growth of producer services industries: sorting through the externalization debate. Growth and Change 22 118-140

Granovetter M (1985) Economic action and social structure: the problem of embeddedness. The American journal of sociology 91 481-510

Jones A (2008) Beyond embeddedness: economic practices and the invisible dimensions of transnational business activity. Progress in Human Geography 32 71-88

Jones M (2009) Phase space: geography, relational thinking, and beyond. Progress in Human Geography $33487-506$

Jones A, Murphy J T (2011) Theorizing practice in economic geography: Foundations, challenges and possibilities. Progress in Human Geography 35 366-392 
Lave J, Wenger E (1991) Situated learning. Legitimate peripheral participation. Cambridge: Cambridge University Press

McCann E J (2011) Urban policy mobilities and global circuits of knowledge: Toward a research agenda. Annals of the Association of American Geographers 101 107-130

Marshall A (1890) Principles of Economics London: Macmillan

Martin R, Sunley P (2003) Deconstructing clusters: chaotic concept or policy panacea. Journal of Economic Geography 3 5-35

Maskell, P (2014) Accessing remote knowledge - the roles of trade fairs, pipelines, crowdsourcing and listening posts. Journal of Economic Geography 14 (5) 883-902.

Miles I (2001) Services innovation: A reconfiguring of innovation studies. PREST discussion paper series Available from http://les.man.ac.uk/prest

Morgan G (2001) Transnational communities and business system. Global Networks 1 113130

Pinch S, Henry N, M J, Stephen T (2004) From 'Industrial Districts' to Knowledge Clusters: a Model of Knowledge Dissemination and Competitive Advantage in Industrial Agglomerations. Journal of Economic Geography 3 373-388

Sparrow P (2012) Global knowledge management and international HRM. In Handbook of Research in International Human Resource Management Eds G Stahl, I Bjorkman, S Morris. Cheltenham: Edward Elgar, 117-141

Storper M, Christopherson S (1987) Flexible specialization and regional industrial agglomerations: the case of the US motion picture industry. Annals of the Association of American Geographers 77 104-117

Storper M, Venables A J (2004) Buzz: face-to-face contact and the urban economy. Journal of Economic Geography 4 351-370 
Uzzi B, Lancaster R (2003) Relational embeddedness and learning: the case of bank loan managers and their clients. Management Science 49 383-399

Vallance P (2011) Relational and dialectical spaces of knowing: knowledge, practice, and work in economic geography. Environment and Planning A 43 1098-1117

Wenger E (1998) Communities of practice: learning meaning and identity. Cambridge: Cambridge University Press

Wood S, Reynolds J (2012) Managing communities and managing knowledge: strategic decision making and store network investment within retail multinationals. Journal of Economic Geography 12 539-565

Yeung H W-C (2003) Practicing new economic geographies: a methodological examination. Annals of the Association of American Geographers 93 442-462

Yeung H W-C (2005) Organizational space: a new frontier in international business strategy? Critical perspectives on international business $1219-240$ 